\title{
$\nabla$
}

\section{Oxidative stress in patients with endemic pemphigus foliaceus and healthy subjects with anti-desmoglein 1 antibodies ${ }^{*}$}

\author{
Ericson Leonardo Gutierrez ${ }^{1,2}$ \\ Lucia Seminario-Vidal ${ }^{5}$ \\ Gerardo Ronceros ${ }^{3}$
}

\author{
Willy Ramos ${ }^{3,4}$ \\ Mercedes Tello 6 \\ Alex G. Ortega-Loayza ${ }^{7}$
}

DOI: http:/ / dx.doi.org/10.1590/abd1806-4841.20186211

\begin{abstract}
BACKGROUnD: Previous studies have shown oxidative stress in pemphigus vulgaris and pemphigus foliaceus, nevertheless, it remains unknown whether a similar response is characteristic of endemic pemphigus foliaceus in Peru.

ОвјестіVеs: To determine the oxidative stress response in endemic pemphigus foliaceus patients and subjects with positive for anti-desmoglein1 antibodies (anti-dsg1) from endemic areas of Peru.

Subjects And METHODS: This is a cross-sectional study. The study population included 21 patients with Endemic Pemphigus foliaceus and 12 healthy subjects with anti-dsg1 antibodies from the Peruvian Amazon (Ucayali), as well as 30 healthy control subjects. Malondialdehyde, an indicator of lipid peroxidation by free radicals, was measured in serum.

RESULTS: We collected 21 cases of endemic pemphigus foliaceus, 15 of them with active chronic disease and 6 in clinical remission. Serum malondialdehyde values in patients with chronic active evolution and healthy subjects with anti-dsg1 antibodies were statistically higher than those of healthy controls $(\mathrm{p}<0.001)$. There was no significant difference between serum values of localized and generalized clinical forms.

Study LimitATIONS: The main limitation of this present study is the small number of patients with endemic pemphigus and healthy subjects positive for desmoglein 1 antibodies.

Conclusions: The increased serum levels of malondialdehyde in patients with chronic active endemic pemphigus foliaceus and healthy subjects from endemic areas with anti-dsg1 antibodies may suggest a contribution of systemic lipid peroxidation in the pathogenesis of endemic pemphigus foliaceus.
\end{abstract}

Keywords: Malondialdehyde; Oxidative stress; Pemphigus; Peru

\section{INTRODUCTION}

Endemic Pemphigus foliaceus (EPF) or Fogo Selvagem is an autoimmune skin disease characterized by the appearance of superficial subcorneal blisters and anti-epidermic circulating autoantibodies, predominantly IgG4, directed against the desmosomal glycoprotein of the cadherin group known as Desmoglein 1 (dsg1). ${ }^{1}$ EPF can be seen in rural areas of some states of Brazil, Colombia, Paraguay, Peru and Tunisia. ${ }^{2-6}$
In Peru, EPF foci have been described mainly within the department of Ucayali. ${ }^{7,8} \mathrm{~A}$ previous study from our group indicated that $8 \%$ of the patients with endemic skin diseases from 3 locations within the Amazon rainforest were diagnosed with EPF. ${ }^{8}$

It has been suggested that healthy subjects exposed to the local ecology of the endemic focus produce anti-dsg1 antibodies due to exposure to environmental factors. ${ }^{9}$ The exposure to hema-

\footnotetext{
Received on 29.06.2016.

Approved by the Advisory Board and accepted for publication on 18.08.2017.

Work performed at the Instituto de Investigaciones Clínicas, Universidad Nacional Mayor de San Marcos (UNMSM) - Lima, Perú. Financial support: None. 
tophagous insects would trigger an immune response in patients with EPF. There is a high prevalence of black flies $(87 \%)$, kissing bugs $(67 \%)$, and bed bugs $(60 \%)$ bites in EPF patients. ${ }^{2}$ Moreover, some endemic areas for EPF coincide with endemic áreas of cutaneous leishmaniasis and Chagas disease. ${ }^{2}$ Our group found that of 41 healthy subjects from the endemic focus of Pueblo Libre (Ucayali, Peru), 31.7\% were positive for anti-dsg1 antibodies. ${ }^{9}$

Previous studies indicated that the oxidative stress response is increased in patients with pemphigus vulgaris (PV) and PF. ${ }^{10-13}$ Furthermore, a positive correlation between anti-dsg1 levels and oxidative markers levels has been recently described. ${ }^{11}$ These observations suggest that healthy subjects with anti-dsg1 may also have an increase in their serum oxidative markers.

Damage by reactive oxygen species is a consequence of an oxidative/antioxidative imbalance. This damage is mediated by reactive oxygen species that react with lipids, proteins and nucleotides. Lipid peroxidation occurs when peroxidant components react with unsaturated fatty acids of lipid membranes and produce changes in its physical and chemical properties, thus, altering cell permeability to fluids and increasing the risk of cell membrane rupture. ${ }^{14}$

To our knowledge, no studies have been carried out in Latin American subjects with EPF. Therefore, our objective is to investigate whether alterations in the oxidative stress response occur in patients with EPF and in healthy subjects with positive anti-dsg1 antibodies from endemic areas of Peru.

\section{METHODS}

This is a cross-sectional study including patients from Lima and Ucayali, carried out between January 2006 and December 2007. Lima is a non-endemic area for PF, while some geographic areas of Ucayali (Campo Verde, Calleria and Nueva Requena) are endemic focus for PF and is located in the Amazon rainforest. ${ }^{5}$ The study population included 21 patients with EPF and 12 healthy subjects with anti-dsg1 antibodies from Ucayali, as well as 30 healthy control subjects from Lima.

Subjects were included if they were 18 years or older and capable of giving informed consent. Subjects with chronic concomitant medical conditions, as well as subjects with acute diseases were excluded. Study subjects were divided in four groups, (1) subjects with chronic active evolution, (2) subjects with disease remission, (3) healthy subjects positive for anti-dsg1 antibodies and (4) healthy control subjects. Samples from patients with active disease were obtained just before starting treatment. Patients in remission were undergoing treatment receiving systemic corticosteroids.

All participants were subjected to a full body skin examination. Blood samples and skin biopsies were collected to determine the presence of anti-dsg1 antibodies (analyzed by ELISA, indirect and direct immunofluorescence), as previously described. ${ }^{9} \mathrm{All}$ sera were separated and stored at $-80^{\circ} \mathrm{C}$ until used.

We quantified malondialdehyde (MDA) as thiobarbituric acid reactive substance (TBARS), following the method of Buege and Aust with some modifications, which is based in the reaction of MDA with thiobarbituric acid (TBA). In the TBA test reaction, MDA and TBA react to form a pink pigment. ${ }^{15}$ Procedure used $0.5 \mathrm{ml}$ plasma, with $1 \mathrm{ml}$ of trichloroacetic acid (TCA 20\%) was added and the tube was left to stand for $10 \mathrm{~min}$ at room temperature. After centrifugation at 3,500 rpm for $10 \mathrm{~min}$, the supernatant was separated. Thereafter, $0.5 \mathrm{ml}$ of the supernatant was added to $0.5 \mathrm{ml}$ of thiobarbituric acid (TBA) and incubated in a boiling water bath for 30 min. After cooling in cold water, the absorbance was read at $532 \mathrm{~nm}$. TBARS concentration was calculated using $1.56 \times 10^{5} \mathrm{M}^{-1} \mathrm{~cm}^{-1}$ as mol/L extinction coefficient. The results were expressed as $\mu \mathrm{mol} / \mathrm{L}$. The MDA levels of oxidative stress and desmoglein 1 antibodies were obtained from plasma and serum respectively.

For the statistical analysis SPSS version 22.0 (SPSS Inc., Chicago, IL, USA) was used. Univariate analysis was performed with frequencies, percentages, media, medians and standard deviation. Plots were used to describe the MDA levels and their median.

For the bivariate analysis, chi square test, Pearson correlation (r), Kruskal Wallis test for independent samples and the Dunn-Bonferroni test for post hoc analysis were used. Since the MDA concentration levels did not have a normal distribution, we use the Kruskal Wallis test to compare para k independent samples. Calculations were made with a confidence level (CI) of 95\%. P values were considered significant if $\mathrm{p}$ was $<0.05$.

The study was approved by the board members of research and ethics of the Clinical Research Institute at Universidad Nacional Mayor de San Marcos, Lima, Peru.

\section{RESULTS}

Twenty-one patients with EPF, 12 healthy subjects from endemic areas, and 30 healthy controls from non-endemic areas were enrolled in this study. Fifteen patients presented with active chronic disease and 6 patients were in clinical remission. Patients had subcorneal acantholysis in their histopathological examinations and were positive for anti-dsg1 antibodies in immunological probes (ELISA 63.6\%, direct immunofluorescence 9.1\% and indirect immunofluorescence $37.3 \%$ ). Demographic characteristics for each group are summarized in table 1 . The disease was more frequent in females, children and young adults.

Levels of lipid peroxidation were compared between groups by measuring MDA serum concentrations, as indicated in the methods section. In patients with the localized clinic form, serum MDA values were between 2.4 and $11.4 \mu \mathrm{Mol} / \mathrm{L}$, for the generalized clinic form were between 2.9 and $5.3 \mu \mathrm{Mol} / \mathrm{L}(\mathrm{p}=0.591)$ (Graph 1).

In patients with chronic active disease, MDA values were between 2.35 and $11.40 \mu \mathrm{Mol} / \mathrm{L}$; these levels were higher than controls (Table 1). Patients in clinical remission had serum levels of MDA between 0.40 and $4.18 \mu \mathrm{Mol} / \mathrm{L}$ (Graph 2, Table 1). Healthy subjects from endemic areas who tested positive for antibodies anti-dsg1 also had serum levels of MDA higher than the controls, ranging between 0.38 and $8.36 \mu \mathrm{Mol} / \mathrm{L}$; while that in the control group serum MDA levels were between 1.49 and $2.59 \mu \mathrm{Mol} / \mathrm{L}$. There was statistically significant difference between the groups based on the MDA levels (Kruskal Wallis; $\mathrm{p}<0.001$ ). The results of the Dunn-Bonferroni test are showed in table 2.

There was no correlation between the serum concentration of MDA and age $(r=-0.105 ; p=0.721)$. Moreover, there was no statistically significant difference in the serum concentration of MDA between males and female patients (U-Mann Whitney Test; $\mathrm{p}=0.196$ ). 
TABLE 1: Characteristics of EPF patients, healthy subjects positives for antibodies anti-dsg1, and healthy subjects from non endemic areas

\begin{tabular}{|c|c|c|c|c|c|}
\hline Characteristics & EPF active form & Positive anti-dsg1 & Control group & EPF in remission & p value \\
\hline Subjects (n) & 15 & 12 & 30 & 6 & ------ \\
\hline Age (years) & & & & & $0.630(* *)$ \\
\hline Media & $28.9 \pm 14.5$ & $28.3 \pm 17.1$ & $30.7 \pm 13.2$ & $23.2 \pm 7.6$ & \\
\hline Median & 32.0 & 24.0 & 29.5 & 21.5 & \\
\hline Sex & & & & & $0.928\left(^{*}\right)$ \\
\hline Male & $46.7 \%$ & $41.7 \%$ & $53.3 \%$ & $33.3 \%$ & \\
\hline Female & $53.3 \%$ & $58.3 \%$ & $46.7 \%$ & $66.7 \%$ & \\
\hline Serum levels of MDA $(\mu \mathrm{Mol} / \mathrm{L})$ & & & & & $<0.001(* *)$ \\
\hline Media & $4.3 \pm 2.2$ & $3.9 \pm 2.5$ & $2.0 \pm 0.4$ & $3.2 \pm 1.5$ & \\
\hline Median & 3.9 & 3.0 & 2.0 & 3.9 & \\
\hline
\end{tabular}

$(*)$ Chi-square test.

$(* *)$ Kruskal Wallis test.

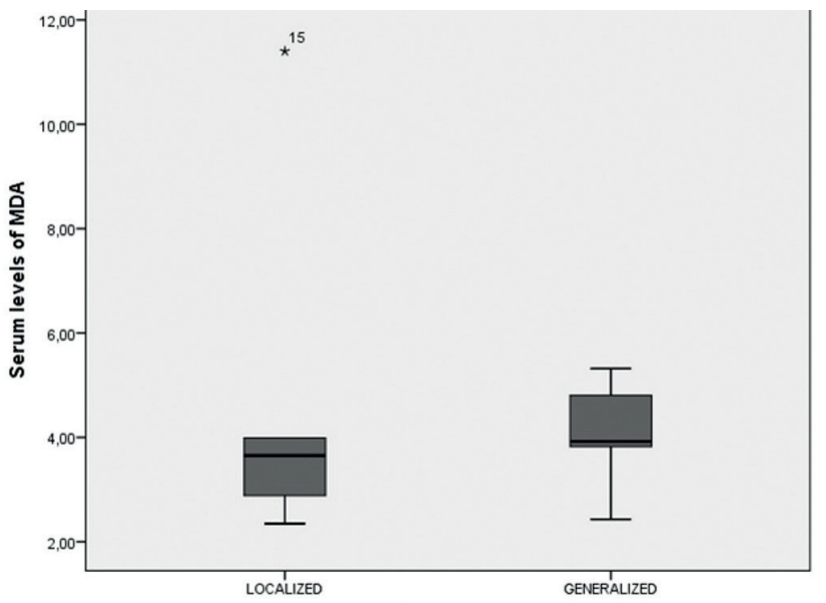

GraPH 1: Median of serum concentration of MDA ( $\mu \mathrm{Mol} / \mathrm{L})$ according to clinical presentation in EPF patients $(p=0.591)$

\section{DISCUSSION}

Recent studies have demonstrated the existence of higher levels of lipid peroxidation in several skin diseases such as vitiligo, rosacea and acne; in skin conditions with systemic component such as psoriasis and pemphigus vulgaris, as well as in systemic diseases with cutaneous manifestations, i.e., systemic lupus erythematous, Behcet's disease and systemic sclerosis. ${ }^{10,11,16-24}$ These studies propose that an imbalance of the oxidative/antioxidant response is necessary for disease pathogenesis or activation.

Only a few studies evaluating the oxidative state in blistering diseases have been done, including patients with pemphigus vulgaris and/or pemphigus foliaceus. ${ }^{10-13}$ Naziroglu et al. ${ }^{13}$ found higher MDA levels in the serum of patients with PV in comparison to healthy controls. Abida et al. ${ }^{11}$ obtained similar results between the sera from patients with $\mathrm{PV}$ and $\mathrm{PF}$, which were higher than healthy controls. In another study, Abida et al. ${ }^{10}$ demonstrated that MDA concentrations were higher in biopsies of lesions from patients with PF and in biopsies from non-lesional skin from PF patients than in biopsies from healthy control subjects. However, no studies have investigated the endemic forms of these two diseases. To our knowledge our study is the first one that illustrates the pres-

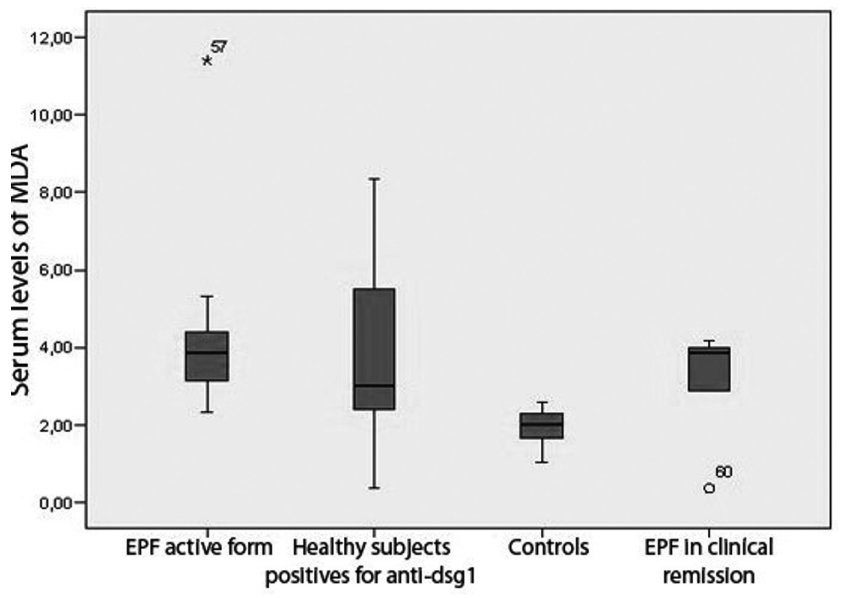

Graph 2: Median of serum concentration of MDA ( $\mu \mathrm{Mol} / \mathrm{L})$ in EPF patients, healthy subjects who tested positive for anti-dsg1 antibodies and healthy subjects from non-endemic areas $(\mathrm{p}<0.001)$

\begin{tabular}{llcccc}
\multicolumn{5}{c}{ TABLE 2: Post hoc analysis results using the Dunn-Bonferroni test } \\
Reference & Groups & $\begin{array}{c}\text { Test } \\
\text { statistic }\end{array}$ & $\begin{array}{c}\text { Standard } \\
\text { error }\end{array}$ & $\begin{array}{c}\text { Standard } \\
\text { deviation }\end{array}$ & $\begin{array}{c}\text { P } \\
\text { value }\end{array}$ \\
\hline & $\begin{array}{l}\text { Healthy } \\
\text { subjects with } \\
\text { anti-dsg 1 }\end{array}$ & 20,750 & 6,260 & 3,315 & 0.001 \\
Controls & $\begin{array}{l}\text { EPF active } \\
\text { form }\end{array}$ & 29,700 & 5,796 & 5,124 & 0.006 \\
& $\begin{array}{l}\text { EPF in clinical } \\
\text { remission } \\
\text { should start } \\
\text { with numbers }\end{array}$ & $-22,500$ & 8,197 & $-2,745$ & 0.000 \\
\hline
\end{tabular}

ence of abnormalities in the oxidative response from patients with EPF in South America.

Altogether, our results and those from other studies, i.e., (1) the positive correlation between anti-dsg1 levels and MDA levels, 2) the observation of increased MDA levels in biopsies from non-lesional skin from PF patients, and 3) the increased MDA levels in healthy subjects with positive anti-dsg1 antibodies suggest that the increase in the oxidative response might precede or concur with the development of skin lesions and it may play a role in the pathogen- 
esis of the disease. Abida et al. ${ }^{(11)}$ proposed that the increase of reactive oxygen species and lipid peroxidation might induce oxidative changes in the structure of Dsg1 and Dsg 3 and therefore would make them potential targets for autoantibodies inducing acantholysis. However, further studies are needed to determine whether the alteration in the oxidative response precedes or not the development of anti-dsg1 antibodies.

Our results also indicate that patients in clinical remission have higher values of serum MDA, which is greater than the controls and less than those of patients with chronic active form. These results suggest that even though there is remission from the clinical and immunological standpoint (less values and titles in ELISA and IFI); there is still biochemical activity of the disease. As a result, determination of MDA in serum could constitute an indicator of disease activity in the group of EPF patients without comorbidities. It is noteworthy to mention, that the localized and generalized clinical forms show similar MDA levels, which suggests that the extension of the disease has no implications in the levels of lipid peroxidation.

Based on our results and previous studies, future research exploring the use of antioxidants (external supplementation or in regular diet) in reducing the oxidative stress is guaranteed. ${ }^{25,26}$

\section{REFERENCES}

1. Di Zenzo G, Zambruno G, Borradori L. Endemic pemphigus foliaceus: towards understanding autoimmune mechanisms of disease development. J Invest Dermatol. 2012;132:2499-502.

2. Sousa JX Jr, Diaz LA, Eaton DP, Hans-Filho G, Freitas EL, Delgado L, et al. Profile of Trypanosoma cruzi Reactivity in a Population at High Risk for Endemic Pemphigus Foliaceus (Fogo Selvagem). Am J Trop Med Hyg. 2012;87:675-80

3. Abreu-Velez AM, Howard MS, Jiao Z, Gao W, Yi H, Grossniklaus HE, et al. Cardiac autoantibodies from patients affected by a new variant of endemic pemphigus foliaceus in Colombia, South America. J Clin Immunol. 2011;31:985-97.

4. Aldama A, Correa J, Rivelli V, Mendoza G. Tipos y variantes de Pénfigo en el Hospital Nacional de Paraguay. Revisión de 70 casos. Med Cutan Iber Lat Am. 2000;28:242 -7.

5. Ramos W, Chacon GR, Galarza C, Gutierrez EL, Smith ME, Ortega-Loayza AG. Endemic pemphigus in the Peruvian Amazon: epidemiology and risk factors for the development of complications during treatment. An Bras Dermatol. 2012;87:838-45

6. Abida 0, Kallel-Sellami M, Joly P, Ben Ayed M, Zitouni M, Masmoudi A, et al. Antidesmoglein 1 antibodies in healthy related and unrelated subjects and patients with pemphigus foliaceus in endemic and non-endemic areas from Tunisia. J Eur Acad Dermatol Venereol. 2009;23:1073-8.

7. Ortega-Loayza AG, Ramos W, Gutierrez EL, Jimenez G, Rojas I, Galarza C. Endemic pemphigus foliaceus in the peruvian Amazonia. Clin Exp Dermatol. 2013;38:594-600.

8. Gutierrez EL, Galarza C, Ramos W, Tello M, Jiménez G, Ronceros G, et al. Skin diseases in the Peruvian Amazonia. Int J Dermatol. 2010;49:794-800.

9. Ortega Loayza AG, Ramos W, Elgart G, Bouman P, Jiménez G. Avila J, et al. Antibodies against desmoglein 1 in healthy subjects in endemic and nonendemic areas of pemphigus foliaceus (fogo selvagem) in Peru. Int $\mathrm{J}$ Dermatol. 2006;45:538-42.

10. Abida 0, Gargouri B, Ben Mansour R, Mseddi-Djemal M, Masmoudi A, Ben Ayed $M$, et al. Biomarkers of oxidative stress in epidermis of Tunisian pemphigus foliaceus patients. J Eur Acad Dermatol Venereol. $2013 ; 27: e 271-5$.

11. Abida O, Ben Mansour R, Gargouri B, Ben Ayed M, Masmoudi A, Turki H, et al. Catalase and Lipid Peroxidation Values in Serum of Tunisian Patients with Pemphigus Vulgaris and Foliaceus. Biol Trace Elem Res. 2012;150:74-80.
Moreover, it would be necessary to establish if antioxidants could be used not only as adjuvant therapy on patients with endemic pemphigus but also as prophylaxis in healthy subjects positive for desmoglein 1 antibodies.

The main limitation of this present study is the small number of patients with endemic pemphigus and healthy subjects positive for desmoglein 1 antibodies; however, the results are still relevant in the studied subjects.

\section{CONCLUSIONS}

In conclusion, this study indicates that patients with chronic active EPF and healthy subjects of endemic areas with anti-dsg1 antibodies have systemic oxidative alterations. This may suggest a contribution of systemic lipid peroxidation in the pathogenesis of $\mathrm{EPF}$; however, it is still necessary further research to confirm whether oxidative stress occurs as direct consequence of the inflammatory response in this disease. $\square$

\section{ACKNOWLEDGMENTS}

We appreciated the expertise and guidance of MSc. Raquel Oré and Dr Carlos Galarza - both passed away in recent years.

12. Yesilova Y, Ucmak D, Selek S, Dertlioğlu SB, Sula B, Bozkus F, et al. Oxidative stress index may play a key role in patients with pemphigus vulgaris. J Eur Acad Dermatol Venereol. 2013;27:465-7

13. Naziroğlu M, Kökçam I, Simşek H, Karakilçik AZ. Lipid peroxidation and antioxidants in plasma and red blood from patientswith pemphigus vulgaris. $J$ Basic Clin Physiol Pharmacol. 2003;14:31-42.

14. Poljsak B. Strategies for Reducing or Preventing the Generation of Oxidative Stress. Oxid Med Cell Longev 2011; 2011:1-15.

15. Buege JA, Aust SD. Microsomal lipid peroxidation. Methods Enzymol. 1978:52:302-10.

16. Koca R, Armutcu F, Altinyazar HC, Gürel A. Oxidant-antioxidant enzymes and lipid peroxidation in generalized vitiligo. Clin Exp Dermatol. 2004;29:406-9.

17. Ines D, Sonia B, Riadh BM, Amel el G, Slaheddine M, Hamida T, et al. A comparative study of oxidant-antioxidant status in stable and active vitiligo patients. Arch Dermatol Res. 2006;298:147-52.

18. Oztas MO, Balk M, Ogüs E, Bozkurt M, Ogüs $1 \mathrm{H}$, Ozer N. The role of free oxygen radicals in the aetiopathogenesis of rosacea. Clin Exp Dermatol. 2003;28:188-92.

19. Briganti S, Picardo M. Antioxidant activity, lipid peroxidation and skin diseases. What's new. J Eur Acad Dermatol Venereol. 2003;17:663-9.

20. Yildirim M, Inaloz HS, Baysal V, Delibas N. The role of oxidants and antioxidants in psoriasis. J Eur Acad Dermatol Venereol. 2003;17:34-6.

21. Turgay M, Durak I, Erten S, Ertugrul E, Devrim E, Avci A, et al. Oxidative stress and antioxidant parameters in a Turkish group of patients with active and inactive systemic lupus erythematosus. APLAR J Rheumatol. 2007;10:101-6.

22. Buldanlioglu S, Turkmen S, Ayabakan HB, Yenice N, Vardar M, Dogan et al. Nitric oxide, lipid peroxidation and antioxidant defence system in patients with active or inactive Behçet's disease. Br J Dermatol. 2005;153:526-30.

23. Najim RA, Sharquie KE, Abu-Raghif AR. Oxidative stress in patients with Behcet's disease: I correlation with severity and clinical parameters. J Dermatol. 2007:34:308-14.

24. Simonini G, Cerinic MM, Generini S, Zoppi M, Anichini M, Cesaretti C, et al Oxidative stress in Systemic Sclerosis. Mol Cell Biochem. 1999;196:85-91.

25. Rajendran P, Nandakumar N, Rengarajan T, Palaniswami R, Gnanadhas EN Lakshminarasaiah $\mathrm{U}$, et al. Antioxidants and human diseases. Clin Chim Acta. 2014;436:332-47.

26. Pisoschi AM, Pop A. The role of antioxidants in the chemistry of oxidative stress: A review. Eur J Med Chem. 2015;97:55-74.

How to cite this article: Gutierrez EL, Ramos W, Seminario-Vidal L, Tello M, Ronceros G, Ortega-Loayza AG. Oxidative stress in patients with endemic pemphigus foliaceus and healthy subjects with anti-desmoglein 1 antibodies. An Bras Dermatol.2018;93(2):212-5. 